\title{
Conflictividad laboral en el sector industrial durante la década del setenta. El caso de los trabajadores de la industria frigorífica de Berisso 1969-1972.
}

\author{
Agustín Nava \\ Universidad Nacional de La Plata, Argentina \\ agustinnava82@ hotmail.com
}

Cita sugerida: Nava, A. (2018). Conflictividad laboral en el sector industrial durante la década del setenta. El caso de los trabajadores de la industria frigorífica de Berisso 1969-1972. Anuario del Instituto de Historia Argentina, 18(2), e079. https://doi.org/10.24215/2314257Xe079 


\section{Conflictividad laboral en el sector industrial durante la década del setenta. El caso de los trabajadores de la industria frigorífica de Berisso 1969-1972.}

\section{Labor conflicts in the industrial sector during the seventies. The case of the workers of the meat plants of Berisso} 1969-1972.

Agustin Nava

Universidad Nacional de La Plata, Argentina

agustinnava82@hotmail.com

\section{Resumen:}

El presente trabajo se inscribe dentro del campo de estudios sobre la historia del movimiento obrero durante los años 60 y 70 en la Argentina y tiene como propósito analizar más específicamente la dinámica gremial y la conflictividad laboral de un actor particular dentro del movimiento obrero de la región del Gran La Plata: los trabajadores de los frigoríficos Swift y Deltec ubicados en el partido de Berisso. A través de un análisis tanto cuantitativo como cualitativo, elaborado a partir de fuentes hemerográficas, análisis de los Informes Laborales del Servicio de Documentación e Información Laboral (DIL) y del Archivo de la Dirección de Inteligencia de la Policía de Buenos Aires (DIPBA), nos enfocaremos en la dinámica que presentó la conflictividad laboral, en la situación por la que atravesaba la actividad en la que estaban insertos dichos trabajadores, la organización interna de los sindicatos estudiados, la dinámica y alineamientos sindicales y las modalidades propias con que tanto el Estado como la patronal intervinieron en los mismos. La finalidad de dicho análisis es poder tanto complejizar y matizar ciertas lecturas e interpretaciones generales sobre el periodo en particular, como profundizar sobre varias temáticas y dimensiones que hacen a las características y dinámica que presenta el movimiento obrero en general.

Palabras Clave: Movimiento obrero, Conflictividad laboral, Trabajadores de los frigoríficos, Gran La Plata.

\section{AbStract:}

This paper is inscribed within of studies on the history of the labor movement during the years '60s and '70s in Argentina and aims to analyze the union dynamics and the labor conflict of a particular actor within the labor movement of the Gran La Plata region: the workers of meat the Swift and Deltec located in Berisso. Through both a quantitative and qualitative analysis, developed from newspaper sources, the Informes Laborales del Servicio de Documentación e Información Laboral (DIL) and Archivo de la Dirección de Inteligencia de la Policia de Buenos Aires (DIPBA), we will focus on the dynamics presented by labor unrest, in the situation that the industry in which these workers were inserted, the internal organization of the trade unions studied, the trade union dynamics and alignment, and the specific modalities with which the State and the employers intervened in them. The purpose of this analysis is to be able to make complex certain readings and general interpretations about the period in particular, as well as to deepen on topics and dimensions referring to the characteristics and dynamics of the workers movement in general.

KEYWORDS: Organized labor, Labor conflicts, Workers of the meat plants, Gran La Plata.

\section{INTRODUCCIÓN}

El presente trabajo forma parte de una investigación más amplia que versa sobre el movimiento obrero de la región del Gran La Plata ${ }^{1}$, y tiene como objetivo más específico en este artículo abordar la dinámica gremial y la conflictividad laboral de un actor particular dentro del movimiento obrero regional: los trabajadores de los frigoríficos Swift y Deltec ubicados en el partido de Berisso. La finalidad, en última instancia, es poder contribuir, por medio de un estudio de caso, al análisis del proceso de protesta social que tuvo lugar en la Argentina durante las décadas del sesenta y setenta. En este sentido, este trabajo además se enfoca en un momento también muy particular de la historia del movimiento obrero argentino, en lo que se podría considerar como el “ocaso" de la "Revolución Argentina” (1969-1972). 
La dictadura que se inicia en 1966 con el golpe de Estado de Onganía intentó concretar un proyecto político y económico que implicaba una redefinición del papel de la clase obrera en la vida económica, social y política del país. Sin embargo, las iniciativas tendientes a reformar aspectos estructurales de la economía y de las instituciones políticas se transformaron en la base de un creciente proceso de radicalización político y social, que afectó a distintos sectores (entre ellos a la clase obrera), y que se materializó de manera más nítida con los grandes levantamientos de masas que se produjeron a partir del mes de mayo de 1969.

No obstante, el caso que analizaremos, si bien representa un conflicto que tuvo cierta centralidad durante las décadas del sesenta y del setenta, de todos modos tiene la particularidad de no ajustarse a este esquema de radicalización política y social. No estaríamos sugiriendo o suponiendo que habría que negar la importancia y magnitud de estos procesos. Sí, por el contrario, nos parece pertinente intentar superar cierta "narrativa triunfalista" -muchas veces presente en los análisis sobre el período (Nieto, 2016; Tortti, 2003)-, la cual da relevancia al objeto de estudio -ya sean conflictos, organizaciones o regiones- a partir de su "intensidad" inusitada o bien de la "espectacularidad" de su experiencia.

En este sentido, consideramos fundamental optar por una definición amplia de conflicto laboral. Nuestra unidad de análisis no se circunscribe a una sola de las manifestaciones de la conflictividad (las huelgas o paros), que, si bien son centrales, no agotan por sí mismas la complejidad del accionar gremial y político de la clase trabajadora. El registro de conflictividad obrera utilizado para llevar a cabo este trabajo incluyó, entonces, todas aquellas acciones en las que se haya manifestado una relación de oposición y/o rechazo entre una personificación obrera y cualquier otro sujeto, ya sea que este tipo de acciones se correspondan con las formas más "suaves" del conflicto (el enfrentamiento verbal/escrito), con las acciones en las que predominan las instancias más deliberativas (reuniones, asambleas, etc.) o negociadoras (entrevistas, paritarias, etc.), y finalmente con las modalidades de lucha más disruptivas, tales como las clásicamente consideradas medidas de fuerza (paros o huelgas, trabajo a reglamento, etc.), o los actos, concentraciones, movilizaciones y algunas formas violentas de manifestación. Colocar el foco del análisis en la dinámica de la conflictividad laboral en su acepción más amplia presenta la ventaja de que nos permite, desde nuestro punto de vista, problematizar la diversidad de estrategias y trayectorias que se desarrollan en el interior del movimiento obrero.

Por otra parte, el sujeto en el que nos vamos a enfocar presentaba, además, la particularidad de ser un sector clave de la clase obrera local, de antigua tradición sindical en la zona, forjado tanto por el Partido Comunista durante las décadas del 20 y del 30, como por el peronismo desde mediados de los años 40, pero que a su vez estaba inserto en una actividad que, hacia el periodo que vamos a analizar, comenzaba a perder centralidad en la estructura económica argentina. El cordón industrial de la región del Gran La Plata (ubicado en los partidos de Berisso y Ensenada), estuvo marcado desde las primeras décadas del siglo XX por la centralidad que adquirieron las actividades industriales vinculadas al procesamiento de carnes. Al ser una actividad que se caracteriza por su uso intensivo de mano de obra, no solo gravitó en las características que asumieron las relaciones en el mercado laboral de la región, sino que además determinó que el gremio de la carne jugara un papel clave en el plano político y gremial. Sin embargo, el eclipse paulatino de la industria frigorífica en la región tendió a modificar en parte este panorama. Por añadidura, deberíamos anotar que, como sostiene Gabriela Gresores, el caso Swift en sí mismo tenía una fuerte carga simbólica en la historia argentina:

...desde principios de siglo había sido la punta de lanza del establecimiento de empresas norteamericanas en nuestro país; emblema de los negociados del capital extranjero en la industria frigorífica, denunciados por Lisandro de La Torre en la década del '30 y ventilados en los '70 con el escándalo Swift-Deltec, también era símbolo de las grandes luchas de los obreros de la carne a fines de la década del '10, en el ' 45 y en los '70, cuando la estatización de la empresa -operada en 1971- había servido como reivindicación gremial, junto con el infructuoso reclamo de control obrero de la producción (Gresores, 2001, p. 88).

Independientemente de esta "fuerte carga simbólica", los trabajadores de la carne tuvieron efectivamente una clara centralidad en el mapa de la conflictividad laboral de la región. Si analizamos la conflictividad laboral de la región del Gran La Plata durante el periodo 1969-1972, desde el punto de vista cuantitativo, podemos 
encontrar que uno de los sectores que mayor protagonismo presentaba dentro de los considerados gremios industriales era justamente el de los trabajadores de la industria frigorífica de Berisso, con el 24,4\% de las acciones de conflicto. El caso aquí presentado, entonces, resultó ser uno de los conflictos que adquirió una considerable importancia en el marco regional durante el periodo, dado que se prolongó durante varios meses, involucró a miles de trabajadores y a distintos sectores sociales, y tuvo asimismo un fuerte impacto político.

Bajo la premisa de que un estudio de caso permite tanto realizar un valioso aporte en aras de complejizar y matizar ciertas lecturas e interpretaciones generales sobre el periodo en particular como profundizar sobre varias temáticas y dimensiones que hacen a la características y dinámica que presenta el movimiento obrero en general, el propósito de este trabajo es, entonces, enfocarnos específicamente en la dinámica que presentó la conflictividad tanto desde el punto de vista cuantitativo como cualitativo. Este aspecto será abordado fundamentalmente por medio del análisis de fuentes hemerográficas.

El procedimiento utilizado para la elaboración de la base de datos estuvo basado exclusivamente en la recolección y codificación de material periodístico, en particular del diario El Día de la ciudad de La Plata. La utilización de periódicos como fuente para elaborar índices de protesta social se ha convertido en los últimos años, y no solo en Argentina, en una práctica sociológica muy extendida y desarrollada (Silver, 2005) ${ }^{2}$.

Asimismo, analizaremos la situación por la que atravesaba la actividad en la que estaban insertos dichos trabajadores, la organización interna de los sindicatos estudiados, la dinámica y alineamientos sindicales y las modalidades propias con que tanto el Estado como la patronal intervinieron en los mismos. En el abordaje de estos aspectos, las fuentes hemerográficas fueron complementadas además con el análisis de los Informes Laborales del Servicio de Documentación e Información Laboral (DIL) ${ }^{3}$ y del Archivo de la Dirección de Inteligencia de la Policía de Buenos Aires (DIPBA) ${ }^{4}$.

Con el objetivo de poder articular estas dimensiones de análisis retomaremos el concepto de poder de negociación elaborado por Erick Olin Wright (2000). La importancia de este concepto estriba en que nos permite establecer una primera mediación entre el aspecto más netamente estructural y la dinámica de las luchas. El poder de negociación hace alusión a cuáles son las capacidades potenciales que tienen las clases para realizar sus intereses en el marco de la lucha de clases ${ }^{5}$. En lo que respecta a las capacidades, Wright las agrupa en dos categorías. Por un lado, la que podríamos denominar como poder estructural, que deriva fundamentalmente de la inserción estructural u "objetiva” de los trabajadores dentro del sistema económico, y que a su vez está determinado tanto por la rigidez (o no) que presenta el mercado de trabajo, como por la ubicación estratégica que puede detentar un grupo particular de la clase trabajadora dentro de un sector económico o industria clave. Por otro lado, la del poder asociativo, que hace referencia a los vínculos concretos de que gozan los miembros de la clase obrera y que da cuenta de las diversas formas de poder resultantes de las distintas modalidades de organización colectiva de las que participan los trabajadores (sindicatos, partidos políticos, etc.)

La gran mayoría de los trabajos que han tenido por objeto el caso de los trabajadores de los frigoríficos de Berisso (Lobato, 2004; James, 2004; Bretal, 2011, 2016a y 2016b), si bien no han desdeñado el análisis particular de la dinámica de la conflictividad, sí se han enfocado más en la reconstrucción del imaginario, significados, sistemas de valores e ideas que resultan de la experiencia en las fábricas y en la propia comunidad de Berisso. Para complementar este tipo de abordajes, ubicamos el foco tanto en la dinámica de los conflictos -y en la naturaleza de las organizaciones sindicales-, como en el accionar que en torno a estos conflictos desplegó tanto la burguesía como el Estado, al igual que los diversos actores involucrados en los mismos. En este sentido, este trabajo parte también de la hipótesis según la cual la dimensión del enfrentamiento presenta una importancia cardinal en la dinámica de los sujetos sociales (Izaguirre, 2009). 


\section{LAS FÁBRICAS Y SUS TENSIONES}

Desde la instalación de los frigoríficos La Plata Cold Storage en 1904 (que pasa a manos del Swift en 1907) y Armour en 1914, dicha industria se había convertido en la actividad predominante del partido de Berisso, lo que determinaría la fisonomía propia de la ciudad, ya que además de ocupar a un gran número de trabajadores ${ }^{6}$, constituía también un polo de atracción para una serie de industrias subsidiarias que se desarrollaban en torno a ella. De manera que podríamos sostener que el conflicto que analizaremos se desarrolla en torno a una fábrica que se había convertido en el eje de la comunidad local. Como señala Lobato, desde principios de siglo "Berisso se construye como una comunidad obrera donde no es necesario separar los conceptos de 'comunidad' y 'clase' ya que se trata de dos facetas relacionadas por la experiencia de los trabajadores" (Lobato, 2004, p. 37).

Una de las particularidades que en general signaba la experiencia laboral en la industria frigorífica estaba determinada por el hecho de que la misma se caracteriza por una constante fluctuación de su nivel de actividad, la cual es consecuencia del carácter estacional propio de la actividad frigorífica, que obviamente impacta en los niveles de empleo. Dicha circunstancia motivaba no solo la recurrencia de los conflictos dentro de los trabajadores de esa industria, sino que asimismo tenía un fuerte impacto en toda la comunidad. La reducción de las labores cumplidas en los frigoríficos resentía de manera directa el desenvolvimiento comercial e industrial de dicha comunidad, que en buena medida dependía de los salarios percibidos en la fábrica (Lobato, 2004). Por añadidura, durante la década del sesenta la industria frigorífica en general transitaba por una lenta pero constante declinación que era consecuencia, por una parte, de la imposibilidad para conservar sus posiciones en el mercado internacional, toda vez que durante dicha década se asiste al fin de la "relación especial" entre Argentina y el principal mercado de exportación, Gran Bretaña (Schvarzer, 1996, p. 232). Por otra parte, los grandes frigoríficos perdían también paulatinamente sus posiciones en el mercado interno, a instancias de los frigoríficos locales que tenían procesos de elaboración más modernos. A estos factores de largo plazo se les sumarán además ciertos elementos de la coyuntura política de la década del setenta que, como veremos más adelante, influirán en la dinámica que adquiere la denominada "crisis del Swift”. Este declive obviamente impactará en el nivel de empleo. Si para 1958 el Swift empleaba alrededor de 7.550 trabajadores - mientras que el Armour empleaba a 4.600 (Lobato, 2004)-, ya para 1967 el plantel obrero del frigorífico Armour había descendido a 2.720 operarios - mientras que en el Swift se registraba una ocupación de 5.822 obreros y obreras- (DIPBA, Mesa B, Factor Gremial, Legajo 11. Tomo III. Localidad Berisso, octubre de 1967, p. 309).

A su vez, a este contexto más general que estamos comentando, deberíamos agregar un factor central que claramente contribuyó a la declinación de las plantas de Berisso: la propia estrategia empresarial. Hacia 1961 el grupo International Packer Limited (IPL) concentró al conjunto de los principales frigoríficos de capital norteamericano en la Argentina, y pasó a ser propietario de los frigoríficos Swift, Armour, Wilson, Codahy y La Blanca (Treviño, 1972). Las dos plantas de Berisso se aúnan bajo la denominación Swift Armour S. A. En estos frigoríficos, el grupo efectuó una apuesta enfocada principalmente hacia la planta Swift y una inversión casi nula en Armour, que derivó en el cierre de esta planta a fines de 1969. El cierre de las instalaciones del Armour se hizo no obstante bajo el compromiso del grupo de que la planta del Swift absorbería a los trabajadores que quedaban desempleados. Sin embargo, en todo este proceso la marcha de la industria no estuvo exenta de tensiones, en la medida en que las suspensiones periódicas de trabajadores por periodos cortos de tiempo se volvieron cada vez más comunes -como por ejemplo la de casi 1.200 operarios por 30 días en el mes de octubre de 1967 (DIL, Informe No 92, octubre de 1967, p. 7G)-, así como también el otorgamiento de vacaciones anticipadas que originaban un gran malestar entre los trabajadores que eran obligados a salir de vacaciones (hacia fines de 1966 la empresa obliga a 2.500 trabajadores de los dos frigoríficos a tomarse vacaciones anticipadas) (DIPBA, Mesa B, Factor Gremial, Legajo 11. Tomo III. Localidad Berisso, septiembre de 1966, p. 121). 
En 1969 IPL se asoció con una corporación financiera multinacional, Deltec Panamericana Ltd., fuerte acreedor de IPL (Gresores, 2002). Sin embargo, esta fusión no evitó que hacia fines de 1970 el Swift solicitara la convocatoria de acreedores, paralizara sus actividades y anunciara la suspensión de miles de obreros. Independientemente de los factores objetivos a largo plazo de la declinación de las grandes plantas, como sostiene Gresores, esta decisión estuvo más bien relacionada con la estrategia empresarial del grupo

...más orientada a obtener beneficios financieros, privilegiando la toma de ganancias por parte de los propietarios extranjeros. El corto lapso mediado entre el traspaso de las acciones a Deltec (agosto de 1969) y su quiebra, un año después podría estar indicando más una acción tendiente a salvaguardar los intereses del principal acreedor de la empresa, que una intención de desarrollar una estrategia productiva. (Gresores, 2002, p. 370)

De todos modos, luego de que se demostraran por vía judicial diversas prácticas fraudulentas y de vaciamiento de los frigoríficos Swift en Argentina, en beneficio de otros negocios de Deltec, un juez nacional decreta la quiebra de Swift-Deltec en 1971, y designa como liquidador al PEN (Poder Ejecutivo Nacional), quien en adelante administrara la empresa. Todo este proceso no solo repercutió en la región, en tanto Berisso era uno de los centros urbanos fundamentalmente afectados por la crisis de la carne, sino que por su propia entidad tuvo un fuerte impacto a nivel nacional -dada la centralidad de la actividad en la dinámica económica argentina-, que afectó a diversos sectores sociales y políticos. Tengamos en cuenta que la industria frigorífica no solo constituía una pieza clave para el equilibrio del comercio exterior del país, sino que su principal producción era un elemento de gran incidencia en la canasta básica de alimentos, al tiempo que sus principales proveedores constituían uno de los sectores económicos centrales de la argentina: la burguesía ganadera ${ }^{7}$. Los múltiples condicionantes que intervenían en este ámbito determinaron, a su vez, las complejas características que adquirió la problemática.

\section{DINÁMICA SINDICAL}

El eclipse paulatino de la industria frigorífica en la región gravitó obviamente en la situación que los trabajadores de los frigoríficos tuvieron en el mercado laboral. La caída en el nivel de empleo se reflejó en la situación salarial. El propio sindicato reconocía que los trabajadores de la carne habían pasado de gozar de los salarios más elevados del conjunto de la industria argentina en 1954, a percibir a inicios de la década del setenta haberes que en comparación con los de los otros gremios -gráficos, metalúrgicos, textiles, etc.- eran un $30 \%$ más bajos (El Día, 03/10/1970). Efectivamente, tal como puede observarse en la tabla 1, la evolución del salario de los trabajadores de la industria de la carne desde la mitad del siglo XX había quedado rezagada con respecto a la evolución salarial en otras industrias. Dicha circunstancia da cuenta del debilitamiento del poder de negociación de estos trabajadores, fundamentalmente desde el punto de vista estructural.

TABLA 1

Comparación de la evolución salarial por sector de actividad (en pesos por hora obrero)

\begin{tabular}{|l|c|c|}
\hline & $\mathbf{1 9 5 4}$ & $\mathbf{1 9 6 8}$ \\
\hline Gráficos & 4,55 & 124,50 \\
\hline Textiles & 4,80 & 123,80 \\
\hline Metalúrgicos & 4,75 & 135,80 \\
\hline Alimentación & 4,62 & 119,80 \\
\hline Carne & $\mathbf{5 , 2 0}$ & $\mathbf{9 8 , 9 0}$ \\
\hline
\end{tabular}


Independientemente de ello, durante la década del sesenta los trabajadores de los frigoríficos de Berisso desarrollaron distintos tipos de medidas de fuerza para resistir la política de despidos y suspensiones, y para protestar por el evidente deterioro salarial. Durante 1962 la conflictividad alcanzó un momento particularmente crítico. Luego de que fracasaran reiteradamente las negociaciones respecto a la renovación de los convenios colectivos, la Federación Gremial del Personal de la Industria de la Carne (FGPIC) dispuso un plan de lucha que constaba de paros progresivos y sorpresivos, el cual en Berisso tuvo una duración de 110 días. La huelga fue levantada, aunque bajo protesta, en una multitudinaria y agitada asamblea en la que participaron alrededor 7.000 trabajadores $^{8}$. A pesar de la militancia evidenciada, el plan de lucha concluyó, no obstante, en una dura derrota, ya que no solo fueron despedidos muchos de los militantes más activos, sino que también se perdieron varias conquistas que se habían obtenido desde 1946, aspecto que se materializó con la firma de un nuevo convenio en $1964^{9}$.

En parte como consecuencia de este desenlace, la lista histórica del Sindicato de Obreros y Empleados de la Industria de la Carne de Berisso (SOEICB), que respondía a la conducción nacional de la FGPIC liderada por Eleuterio Cardoso, y cuyo candidato local era Manuel Reche, pierde por 300 votos la conducción de la organización a partir de 1965, a manos de una alianza de listas (Lista Rosa de Unidad), de la que participa el comunismo a través de la lista Marrón y también la agrupación El Activista de la Carne de tendencia trotskista (Raimundo, 2015) ${ }^{10}$. Alianza que justamente se conforma para terminar con el cardosismo. El apoyo brindado en dicha ocasión por importantes dirigentes del sindicalismo nacional, tales como Andrés Framini y Augusto Vandor, así como también el apoyo expreso de algunos sindicatos de la zona (ATE Ensenada, 62 organizaciones de La Plata, Berisso y Ensenada, la lista verde de la AOT) no logró revertir el desprestigio de la lista oficialista.

En adelante el mapa político sindical del SOEICB quedará conformado del siguiente modo: la Lista Rosa de Unidad dominará sin demasiadas dificultades la vida política del gremio. Esta lista estaba encabezada por Héctor Guana, quien se convertirá entonces en el secretario general del sindicato durante todo nuestro periodo de análisis. Asimismo, en 1968 Cardozo pierde la conducción de la FGPIC a manos de Constantino Zorila. Sin embargo, el sindicato de Berisso no se alineó con la conducción de la Federación, con la cual mantuvo pocos vínculos (véase $D I L$, informe No 95 , enero de 1968, p. 32) ${ }^{11}$. Hacia 1968 , luego de la ruptura de la CGT en dos centrales, el SOEICB se desvincula también de las mismas sin vincularse con ninguna de las dos CGTs (DIPBA, Mesa B, Factor Gremial, Legajo 11. Tomo III. Localidad Berisso, marzo de 1969, p. 392)

Algunos analistas (Vázquez, 1983) sostienen que la Lista Rosa que encabeza Guana presentaba cierta afiliación política con el partido radical ${ }^{12}$. De todos modos, por lo menos durante nuestro periodo de estudio, no tiene públicamente una actuación política muy profusa. Más aún, en las distintas publicaciones en las que la organización hacía público su programa, se determinaba explícitamente que uno de los objetivos de la Lista Rosa era que "el sindicato no se comprometa en actividades políticas partidistas" (DIPBA, Mesa B, Factor Gremial, Legajo 11. Tomo 4. Localidad Berisso, mayo de 1965, p. 58).

Por su parte, varios informes de la policía que intentaban determinar su "adscripción política" señalan en varias ocasiones que tanto Guana como los demás componentes de la comisión directiva "son personas apolíticas y que se dedican exclusivamente a las funciones gremiales y sociales del gremio" (DIPBA, Mesa B, Factor Gremial, Legajo 11. Tomo 4. Localidad Berisso, 09/04/1973, p. 8). En verdad, tanto de la actividad del sindicato como de los distintos documentos publicitados se desprende que el accionar del mismo durante nuestro periodo de estudio estuvo delimitado primordialmente más por lo que podríamos considerar como una tendencia mutualista. En la gran mayoría de sus expresiones públicas, el SOEICB hacía especial hincapié en su papel de administrador de los recursos económicos del sindicato, y destacaba los distintos beneficios sociales otorgados a los afiliados, que les permitían acceder a una mejor calidad de vida. En el aspecto social, por ejemplo, en general se ponderaba con bastante estima el desarrollo de un policlínico propio, consultorios médicos, seguros, bonificaciones por nacimiento y matrimonio, préstamos 
personales, etc; en el cultural se destacaba la creación de una completa biblioteca pública, talleres de corte y confección, tareas de apoyo a los hijos de los afiliados con dificultades en los niveles primario y secundario, etc. También se promovía el desarrollo de actividades deportivas relegando claramente a un segundo plano las expresiones que hicieran alusión a un proyecto político-ideológico más amplio y que excedieran las demandas más netamente corporativas ${ }^{13}$. Este último aspecto era resaltado asimismo por los informes de la inteligencia policial (DIPBA, Mesa B, Factor Gremial, Legajo 11. Tomo III. Localidad Berisso, 06 /09/1967, p. 271). Claramente, el sindicato en cuestión desplegaba su accionar en una de las tres tendencias en las que se dividió gran parte del movimiento obrero local: el "participacionismo" 14 . Dicha tendencia se caracterizaba fundamentalmente por desarrollar su actividad cuestionando solo aspectos parciales del programa económico, político y social, sin llegar a proponer una alternativa política y económica diferente a la puesta en práctica por el gobierno o la patronal.

Durante nuestro periodo de análisis solo dos agrupaciones de izquierda van a intentar discutirle la hegemonía, aunque sin éxito, al sector liderado por Guana. En primer lugar, se encontraba la lista Blanca y Celeste, orientada por el Partido Comunista, sin demasiada gravitación ni caudal electoral. Por otra lado estaba la Agrupación El Activista de la Carne - Lista Gris, impulsada por militantes y simpatizantes del Partido Revolucionario de los Trabajadores - La Verdad (Castillo, 2011) ${ }^{15}$. Independientemente del grado de inserción y de su desempeño en las elecciones sindicales (en las cuales quedaba a una considerable diferencia de votos respecto de la Lista Rosa), según lo que se desprende de los archivos de inteligencia policial, la agrupación mantuvo una profusa actividad de difusión y de militancia en las establecimientos fabriles, al punto de que en distintos momentos de la década del sesenta y del setenta logra conseguir que un puñado de militantes se convirtieran en delegados de sección (DIPBA, Mesa B, Factor Gremial, Legajo 11. Tomo III. Localidad Berisso, p. 190 y Tomo IV, p. 33). En general, su actividad estaba centrada en las denuncias de las condiciones de trabajo en las que se desarrollaban las tareas en las distintas secciones de los establecimientos, los bajos salarios y las prácticas "burocráticas" de la conducción sindical ${ }^{16}$.

Independientemente de ello, habría que reconocer, sin embargo, que entre los años 1969 y 1972 ambas agrupaciones habían perdido gran parte del peso y gravitación de la que habían gozado (o gozarían) dentro del gremio en otras épocas, de manera que en ningún momento el dominio de la vida política y sindical del gremio que ostentaba la Lista Rosa fue seriamente discutido. Según algunos informes de la policía elaborados en el año 1969, las agrupaciones comunistas o trotzkistas que actuaban en el ámbito de los frigoríficos no poseían "mayor predicamento o gravitación en el gremio" (DIPBA. Mesa B, Factor Gremial, Legajo 11. Carpeta 16. Tomo 3. Localidad Berisso, p. 596). Este aspecto se corrobora si nos detenemos en los resultados de los actos eleccionarios para renovar autoridades. Por ejemplo, en las elecciones de 1967 la Lista Gris y la Blanca y Celeste obtienen 378 y 223 votos respectivamente, frente a los 6.052 que se adjudica la lista oficialista.

Tengamos en cuenta que el SOEICB era, al momento en el que se inicia nuestro periodo de análisis, una organización de cierta antigüedad, mayormente consolidada y que exhibía una importante solidez institucional. Un dato que nos puede dar cuenta de la importancia de dicha organización es que, según se desprende de la información de las elecciones, el sindicato de Berisso contaba hacia principios de 1969 con 7.316 obreros y obreras afiliados y en actividad (DIPBA, Mesa B, Factor Gremial, Carpeta 16. Legajo 11. Tomo 3, Localidad Berisso, p. 11) ${ }^{17}$. Por añadidura, gozaba además de una gran autonomía, en la medida en que la FGPIC, tal como lo indica su nombre, se organizaba bajo una práctica federativa. Como sostiene Zorrilla (1974), en este tipo de organización las unidades de primer nivel presentaban cierta fortaleza, ya que tenían la posibilidad de resistir las decisiones tomadas en el nivel superior y aun desafiliarse sin que ello modificara su capacidad formal de maniobra y acción. 


\section{CARACTERÍSTICAS DE LA CONFLICTIVIDAD LABORAL}

$\mathrm{Al}$ igual que lo señalado por algunos autores que analizan el caso nacional, desde 1969 la conflictividad laboral en general en la región del Gran La Plata acusa una tendencia creciente - tal como puede observarse en la Figura 1-, que alcanza su pico en el año 1971. El movimiento obrero regional incrementó su actividad, entonces, en un contexto signado tanto por un proceso de intensificación general de las luchas sociales, como por contradicciones crecientes en el seno de la Fuerzas Armadas, y entre éstas y los sectores empresariales y políticos (O’Donnell, 2009). Sin embargo, hacia 1972, en un marco sensiblemente distinto al de los años previos -consecuencia de que la "apertura democrática" se encontraba en una etapa bastante avanzada (cuando la "retirada" del régimen militar ya era un hecho incuestionable)-, la tendencia creciente de la conflictividad laboral se revierte sensiblemente, hecho que traza una curva en forma de U invertida ${ }^{18}$.

Este ciclo de protesta obrera regional estuvo marcado, asimismo, por las especificidades propias que presentó la conflictividad de los trabajadores de la industria de la carne de Berisso. Durante nuestro periodo de análisis, el proceso de luchas que llevaron adelante estos trabajadores se inicia hacia fines de 1969, momento en el que se anuncia el cierre de la planta de Armour. Entre 1969 y 1972 dichos trabajadores desarrollaron 137 acciones, cuya tendencia es similar a la que se puede divisar tanto para el movimiento obrero regional como nacional.

FIGURA 1

Conflictos obreros 1969 - 1972. Gran La Plata

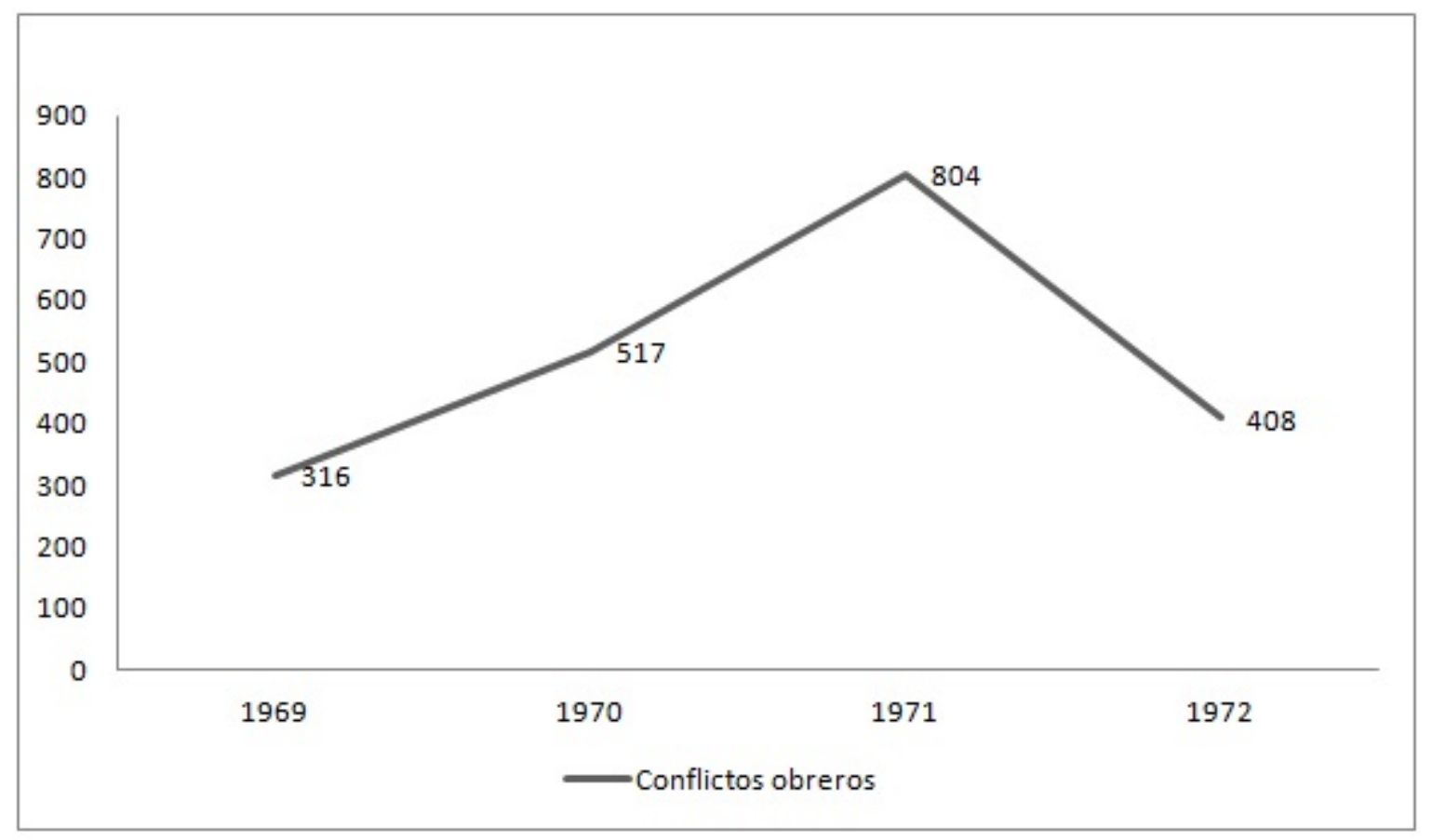

Fuente: elaboración propia con base en información periodística

En el caso particular de los trabajadores de los frigoríficos de la zona -como se puede observar por su parte en la figura 2-, la gran mayoría de los conflictos estuvieron concentrados fundamentalmente durante los años 1970 y 1971 (30,7 \% y el 54,7\% respectivamente). Un rasgo bastante significativo de este proceso de luchas que se inicia en 1969 y concluye en 1972 es que en ningún momento el sindicato impulsa paros, ya sean parciales ${ }^{19}$ o totales (aunque sí movilizaciones o concentraciones en cinco ocasiones), por lo que conflicto se circunscribe a las instancias más deliberativas o negociadoras, tales como las asambleas $(27,7 \%)$ o las entrevistas, negociaciones entre partes, etc. $(16,8 \%)^{20}$, lo que da cuenta de un permanente estado 
deliberativo. El motivo que impulsará a los trabajadores de la carne a movilizarse durante todo el periodo en cuestión será, como es evidente, la defensa de las fuentes de trabajo: más del $50 \%$ de las acciones tiene como objetivo la protesta en contra de las suspensiones o despidos, mientras que solo en un 10,9\% de las acciones la estatización, nacionalización o el control obrero de la producción se plantea como objetivo explícito. Lobato sostiene que de la época de la primera presidencia de Perón, a pesar de haberse logrado la obtención de importantes conquistas, habían quedado dos frustraciones: la sanción de un estatuto de la carne y la nacionalización de las grandes plantas. Como veremos más adelante, bajo nuestro periodo de estudio, solo pocos sectores obreros en Berisso van a manifestar que la solución a la crisis por la que atravesaba la industria residía en la nacionalización y control obrero de las plantas. Por otra parte, es interesante anotar que, como ya señalamos, de las manifestaciones de casi todas las agrupaciones del sindicato se solía considerar que uno de los objetivos primordiales era volver a conquistar los derechos obtenidos en el convenio firmado en el año 1946, los cuales serían cercenados fundamentalmente luego de la huelga larga de $1962^{21}$.

FIGURA 2

Conflictos de los trabajadores de la carne 1969-1972. Gran La Pata

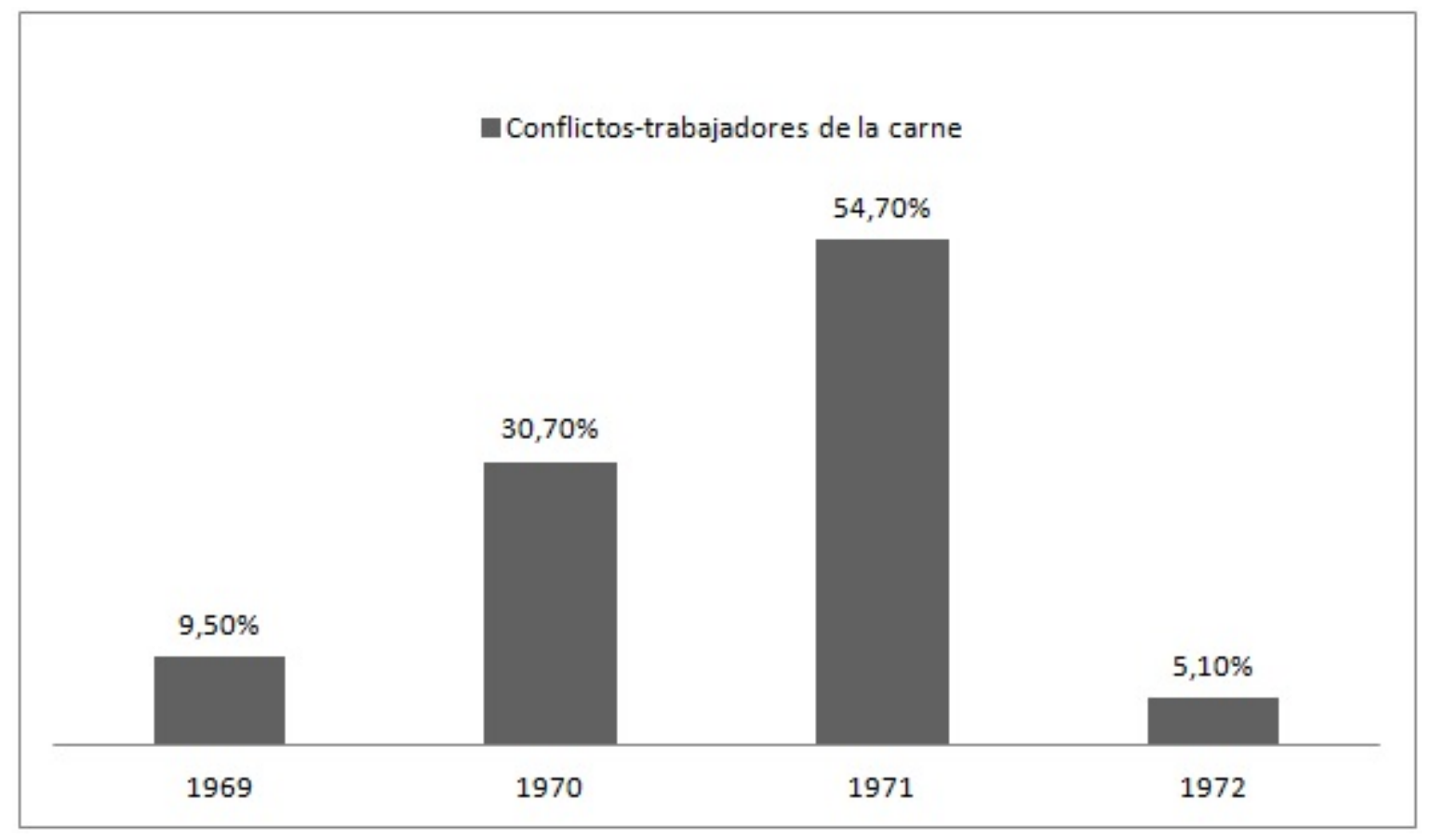

Fuente: elaboración propia con base en información periodística

No obstante, como ya sostuvimos, todos estos focos de conflictividad nunca desembocaron en procesos de lucha o movilizaciones desde las bases, sino que se circunscribieron a los canales de negociación institucional entre dirigentes gremiales y las patronales o autoridades nacionales y provinciales, por lo que la lucha se mantuvo en un plano defensivo.

Los primeros síntomas de la "crisis del Swift" toman estado público, como dijimos, en octubre de 1969, cuando Deltec anuncia que el 31 de diciembre de ese año se cerrarían las puertas del Armour -que se fusionaría con el Swift-, con el argumento, compartido en ese momento por el sindicato de Berisso, de que la planta del Armour se encontraba inhabilitada para faenar por las autoridades sanitarias de la Nación, al no encontrarse en condiciones aptas de operabilidad en las matanzas, según las últimas exigencias del mercado europeo y, de manera especial, de su principal comprador: el Reino Unido. La primera reacción del SOEICB no se dirige a iniciar ningún proceso de confrontación, lo cual nos da la pauta de que, de algún modo, venían negociando la medida con la empresa. Al hacerse pública la decisión de la empresa, la Comisión Directiva del 
sindicato comunica a los operarios del Armour (unos 1.080) que mantengan la más "absoluta tranquilidad". Según el gremio, la fusión de los frigoríficos se haría con estabilidad de los obreros, que conservarían su fuente de ingreso, garantías horarias y gremiales que gozaban en aquel momento. En esta oportunidad, se desarrolla una dinámica que será recurrente a lo largo de todo nuestro periodo de estudio. En primer lugar, las listas opositoras intentaron otorgarle un carácter más activo al proceso, denunciando que el cierre de la planta constituía un atropello más de la empresa apoyado por los dirigentes sindicales, y proponiendo que se convocara una asamblea deliberativa para organizar un plan de defensa de las fuentes de trabajo. La denuncia respecto a la modalidad de Guana de convocar a asambleas de naturaleza más informativa que deliberativa es común y recurrente en las agrupaciones de izquierda ${ }^{22}$. De todos modos, como será una constante a lo largo del conflicto, las bases terminan aceptando los términos impuestos por la comisión directiva del sindicato y la fusión de las dos plantas no da lugar a ningún conflicto desde las bases. Esto ocurre a pesar de que, en este caso particular, Guana tuvo que hacer denodados esfuerzos para convencer a los trabajadores presentes de que aceptaran los términos del acuerdo a través del cual se realizaría el traspaso (DIPBA, Mesa B, Factor Gremial, Carpeta 16. Legajo 11. Tomo 3, Localidad Berisso, noviembre de 1969, p. 501). La estrategia de institucionalización del conflicto de clases y su canalización en instancias de negociación no solo estaba consolidada entre la dirección del SOEICB, sino que además no parece haber sido disputada seriamente desde las mismas bases.

La subordinación del conflicto a las pautas establecidas dentro de los marcos institucionales legales que observaremos en términos generales a lo largo de nuestro periodo de análisis se corrobora si nos detenemos en dos variables que hemos utilizado para captar las formas y características concretas que adquirieron las acciones impulsadas por el movimiento obrero. En primer lugar, hemos elaborado una variable que intenta dar cuenta -en una primera aproximación- de los niveles de radicalización de las acciones, a partir del análisis del grado de violencia material presente en los enfrentamientos, en primer lugar, a partir de una distinción entre los enfrentamientos verbales/escritos y los enfrentamientos materiales. Los valores de esta variable son:

1. enfrentamiento verbal, escrito, etc.;

2. enfrentamiento material, con cuerpos. Puede incluir enfrentamiento verbal;

3. enfrentamiento material, con cosas que no son armas de fuego. Puede incluir enfrentamiento con cuerpos;

4. enfrentamiento material, con armas de fuego. Puede incluir otras cosas que no son armas de fuego.

En el caso de los trabajadores de la carne, ninguna acción llevada adelante por ellos presenta registros para los dos últimos valores (enfrentamiento material, con cosas que no son armas de fuego. Puede incluir enfrentamiento con cuerpos; y enfrentamiento material, con armas de fuego. Puede incluir otras cosas que no son armas de fuego). Estos valores intentan captar las formas de lucha en las que no solo se encuentra implicada la movilización de cuerpos, por ausencia o presencia deliberada de los mismos, sino también aquellas en las que además se utilizaron otro tipo de objetos (que pueden comprender incluso el empleo de armas de fuego).

Por otro lado, otra de las variables que hemos utilizado para aproximarnos al nivel de radicalización de los enfrentamientos es si las acciones se ubicaban fuera o dentro de los marcos que establecía el sistema institucional-legal, y si en las mismas actúan solo las dirigencias sindicales o se evidencia un mayor involucramiento de cuerpos. Nuevamente, en el caso que estamos analizando, se observa como las formas de lucha se encuentran subordinadas por las dirigencias o pautadas por el sistema, al visualizar que las formas que asume el enfrentamiento corresponden casi en su totalidad a las luchas que se entablan dentro del sistema institucional, con presencia de cuadros dirigentes y/o con presencia de masas (99,2\%). Registramos un único hecho que se desarrolla por fuera del sistema institucional y con un mayor involucramiento de los cuerpos en el conflicto. Deberíamos tener en cuenta que el hecho de que este tipo de acciones sean minoritarias es, en algún punto, una tendencia esperable en tanto no forman parte de los modos de lucha recurrente de los 
asalariados en general. Sin embargo, dichos valores, para estas dos variables en el caso de los trabajadores de la carne, se ubican por debajo de la media que encontramos para el movimiento obrero regional en general ( $1,8 \%$ en lo que respecta a la primera variable y $97,7 \%$ para el caso de la segunda).

De todos modos, la tónica de la conflictividad a lo largo de los cuatro años bajo análisis no fue homogénea. La fase más aguda del conflicto se inicia a principios del mes de octubre de 1970. El día 2 de ese mes la empresa anuncia la suspensión de 1.100 obreros en la planta de Berisso y seis días después los trabajadores suspendidos alcanzaban la cifra de 3.700, como consecuencia de la paralización casi absoluta de las actividades en la planta, ya que la empresa deja de comprar hacienda y comienza a agotársele el stock. En este momento en particular, esta situación no era privativa del frigorífico Swift de Berisso, sino que era extensiva a otros establecimientos de la industria. En los Frigoríficos Argentinos (ex Wilson) de Valentín Alsina, Santa Elena y Liebig's en Entre Ríos, La Negra en Avellaneda, Suquerí en Concordia, Swift en Rosario, y otros pertenecientes a CAP (Corporación Argentina de Productores de Carne), también se registraban cierres de establecimientos y suspensiones (DIL, informe $\mathrm{N}^{\circ} 128$, octubre de 1970) ${ }^{23}$.

En nuestro caso en particular, el argumento esgrimido por la empresa era que la paralización de las actividades se debía al elevado precio con el que estaba operando durante esos días el rubro vacunos en el Mercado de Liniers, además de sostener que, a diferencia de otros frigoríficos, no era beneficiaria de líneas de crédito para la compra de hacienda. De manera que el eje de confrontación que delinea el grupo empresarial transnacional no se circunscribe a la relación capital-trabajo, sino que se dirige hacia otros sectores sociales y políticos: en particular hacia la burguesía agroganadera y el Gobierno Nacional. Este último, en momentos en el que se inicia el conflicto, se encontraba presidido por Roberto Levingston, quien intentaba imprimirle a su gestión un tono nacionalista y estatal, lo que derivó en cierta intransigencia en la negociación con la empresa.

La estrategia patronal parece orientarse en este caso más a lograr la integración y la identificación de la fuerza de trabajo con los intereses de la empresa, que a profundizar las vías coercitivas antisindicales. A pesar de que esta tendencia de la empresa a desarrollar una "práctica paternalista" en su relación con los trabajadores se hace extensiva a todo nuestro periodo de análisis, deberíamos aclarar que, no obstante, ante conflictos que escapaban a la dirección sindical reconocida -como por ejemplo el paro de actividades que se suscitó en la sección picada a principios de 1968 por demandas referidas a las condiciones de trabajo-, la patronal activaba mecanismos más represivos tales como el despido de los delegados involucrados, suspensiones, etc. (DIPBA, Mesa B, Factor Gremial, Legajo 11. Tomo III. Localidad Berisso, marzo de 1968, pp. 357, 422) ${ }^{24}$

Cabría destacar que, a diferencia de lo que sucedida en otros casos, desde el Gobierno Nacional, si bien no existió una iniciativa demasiado comprometida para solucionar la situación por la que atravesaban los trabajadores, tampoco se ensayó una respuesta represiva hacia las pocas medidas de acción directa que materializaron los mismos ${ }^{25}$.

A partir de este momento se abre un fuerte debate, que involucra a una multiplicidad de actores sociales y políticos, respecto a cuáles eran las causas, y por supuesto las salidas posibles, de la crisis de la industria frigorífica. En lo que respecta al SOEICB, nuevamente su reacción al principio es claramente defensiva, limitada a repetir el planteo de la patronal. Su acción estuvo orientada principalmente a privilegiar las negociaciones tanto sea con la empresa como con el gobierno nacional o provincial. Los mecanismos de negociación tuvieron un funcionamiento fluido, fundamentalmente con el ejecutivo provincial, aunque basados en la presión ejercida por la movilización del sindicato, el cual en ningún momento fue desconocido como un interlocutor válido.

La exigencia para con el Estado se orientaba principalmente a la puesta en marcha de medidas que protegieran la industria, dirigidas en especial al establecimiento de precios máximos en el mercado de Liniers. Según este planteo, la causa de la crisis de los frigoríficos se debía a la baja productividad ganadera, como consecuencia del predominio de una ganadería extensiva y atrasada. De todos modos, en momentos en que el conflicto se encuentra más avanzado y se dan a conocer el funcionamiento empresarial y financiero del grupo Deltec, Guana se muestra más cauteloso y aclara que "no son cómplices de la política del Swift sino que 
solo buscan proteger la fuente de trabajo de más de 5.000 personas" ( El Día, 23/01/1971 ). Por su parte, la FGPIC, si bien comparte la crítica hacia los productores ganaderos, apunta también que "las grandes plantas de las zonas portuarias son antieconómicas y en buena parte obsoletas", punto sobre el cual se desarrolla cierto debate, ya que desde el mismo sindicato de Berisso no se compartía esta caracterización ${ }^{26}$. En verdad, la Federación planteaba un discurso más combativo, y le exigía al gobierno la nacionalización o estatización de la empresa.

Hay que tener en cuenta, de todos modos, que en un principio la empresa despliega también una estrategia de "argentinización", es decir, de encontrar compradores argentinos para el $51 \%$ de las acciones, aunque esta estrategia presentaba ciertos entreveros que volvían difícil su concreción. En diciembre de 1970 el diario El Día informaba que uno de los posibles compradores era un grupo empresario encabezado por el exministro de Economía, Krieger Vasena. Sin embargo, según la misma fuente, la operación estaba demorada por desacuerdos dentro del mismo Gobierno Nacional. Quien más se resistía a la nacionalización del Swift era el actual ministro de Economía, Aldo Ferrer, en tanto que, como sugiere Gresores, esta estrategia apuntaba más bien a resguardar los intereses del principal acreedor de la empresa. Es interesante que, para el semanario Busines Week de Nueva York, este tipo de operación fuera una modalidad en cierta medida fraudulenta pero corriente en la época. El mecanismo era el siguiente:

\footnotetext{
Una sociedad financiera (...) adquiere una planta exportadora en un país económica o gubernamentalmente subdesarrollado. Esta exporta con destino al holding o a sus subsidiarias, subfacturando, a un precio que puede ser inferior al propio costo. La pérdida en los libros de la empresa local se cubre con préstamos en divisas que otorga el propio holding empleando el beneficio que obtuvo entre el bajo precio de compra y el de posterior venta, sobre el que no ha pagado impuestos. Sin desembolsar un centavo el holding se va transformando en acreedor de su propia empresa y del país. Se trata de obtener luego el solvente comprador local que garantizará el pago de la deuda externa. De ser necesario se movilizan algunos patriotas nativos que en nombre del interés superior de la nación proponen la estatización de la empresa o su transformación en cooperativa obrera (...) La expropiación no aporta riesgos ya que los gobiernos están obligados a respetar las deudas externas en salvaguarda del propio crédito, o como suele decirse, del honor nacional (citado en Gresores, 2002, p. 370).
}

Más adelante, a principios de 1971, trasciende que continuaban las gestiones para promover la reapertura del establecimiento mediante la compra del mismo, pero ahora, por sesenta y cuatro de los ejecutivos del Swift. Sin embargo, nuevamente, según lo informado por el diario El Día, en esferas oficiales existían serias reservas acerca del resultado de las negociaciones, en tanto que se consideraba a los ejecutivos del Swift como simples emisarios del grupo Deltec. De este modo, el grupo retendría las líneas de comercialización de su subsidiaria argentina en el extranjero, y resolvía a la vez la grave dificultad económica por la que atravesaba la misma. Esta sospecha se veía refrendada por el hecho de que la propuesta presentada por los directivos del frigorífico Swift al Poder Ejecutivo en febrero del 1971 solicitaba que en caso de llevarse a cabo la referida operación de compra les fuera concedido un tratamiento crediticio similar al ofertado a las empresas de capital nacional para la compra de hacienda.

No obstante estas vicisitudes, Guana, en un principio, se pronuncia en varias oportunidades en contra de la aplicación de este tipo de soluciones (es decir, tanto de la "argentinización" como de la estatización), citando reiteradamente la "desafortunada" experiencia de los ferrocarriles como ejemplo para manifestarse como no partidario de la administración estatal de ciertas empresas. Más aún, desde el sindicato de Berisso se declaran también en contra de que los trabajadores tomaran el control de la empresa, argumentando que de ese modo no habría quien se hiciese cargo del mantenimiento de su mercado exterior, principal destino de la planta del Swift de Berisso. Por otra parte, insistían en señalar, en varias ocasiones, que la explotación del Swift era altamente rentable, ya que, en opinión de ellos, bajo ningún concepto podía considerarse a la planta de Berisso como un frigorífico obsoleto. Claramente, y en contraste otros casos abordados por la bibliografía sobre el periodo en cuestión, las demandas más radicalizadas -como, por ejemplo, que la empresa quedara en manos de los trabajadores o que simplemente se estatizara- tuvieron escaso arraigo entre los trabajadores de Berisso. De modo que el conflicto estuvo lejos de expresar un perfil abiertamente antipatronal. 
Ni siquiera claramente antidictatorial. Por ejemplo, si analizamos en términos cuantitativos la tendencia en los alineamientos políticos ${ }^{27}$ se puede observar cómo la mayoría de las acciones de los trabajadores de la carne se concentran bajo la categoría rechazo formal (es decir, acciones en las que no se cuestionan de un modo sustancial o global las implicancias del programa económico y político del gobierno), con un 78,8\% del total de los hechos, mientras que los conflictos contra el régimen militar representan solo un $21,2 \%$.

En consonancia con este alineamiento con la postura sostenida desde la empresa, el eje de las negociaciones con la misma en Berisso se circunscribe solo al pago de las "garantías horarias" (norma establecida por los convenios laborales que estaban en vigencia y según la cual, ante la falta de trabajo, se garantizaba un jornal correspondiente a 6 horas y 40 minutos), que tras arduas gestiones terminan siendo abonadas por el Estado Nacional. A pesar de que las distintas agrupaciones o listas opositoras del gremio exigían de manera reiterada la adopción de medidas más enérgicas por parte del SOEICB, es recién en diciembre de 1970 -cuando las perspectivas de solución eran cada vez menores al declararse la convocatoria de acreedores de la empresa y las suspensiones alcanzaban ya casi a 5.000 trabajadores - que el sindicato organiza la primera manifestación hacia el centro de la ciudad de La Plata. La concentración se efectuó frente a la Casa de Gobierno y allí se exigió una entrevista con el entonces gobernador de la provincia de Buenos Aires, el brigadier Horacio Rivara. Ante la presión de la manifestación, el gobernador finalmente accedió al pedido, y recibió a una delegación compuesta por dirigentes tanto de la FGPIC y del SOEICB, como de la Cámara de Industria y Comercio de Berisso y por párrocos de la zona. El pedido central al gobernador en esta ocasión era para que intercediera ante el Gobierno Nacional para lograr audiencias con el ministro del Interior y posteriormente con el general Levingston. A pesar de ser una de las primeras medidas de acción directa que materializa el sindicato en el marco del conflicto, la misma no solo no escapa nunca al control de la conducción de la dirigencia sino que tampoco destaca por su nivel de militancia o radicalidad. Luego de comunicar las gestiones a los trabajadores que se habían concentrado en las afueras de la Casa de Gobierno, los mismos se desconcentraron en orden, a pesar de que en cierto momento algunas personas instaron a los presentes a realizar una manifestación por la Avenida 7, sugerencia que no fue acompañada por los trabajadores.

En un contexto de agudización de la crisis luego de que el ministro de Economía Aldo Ferrer explicitara que no estaba entre sus prioridades establecer canales de ayuda financiera a la empresa, en enero de 1971 se llevó a cabo una nueva y más masiva movilización, que incluyó una reunión con el gobernador Rivara de la que participó nuevamente la Cámara de Comercio e Industria de Berisso, la cual además había decretado una paralización de la actividad comercial. Luego de la entrevista se menciona que una de las soluciones sobre la que estaban trabajando las autoridades sería la de encontrar nuevas fuentes de trabajo para emplear a los desocupados de la planta de Berisso, entre las que se mencionó particularmente la obra del Chocón. Tal alternativa fue rechazada por el gremio, ya que los obreros de Berisso "tenían en esta ciudad su lugar de residencia y familia" ( El Día, 22/01/1971)

Sin perspectivas de solución al conflicto en el corto plazo, en febrero del mismo año, por iniciativa de la Secretaría de Trabajo de la provincia, entra en funcionamiento una "comisión de emergencia", de la que forman parte el sector sindical afectado, además de intendentes, dirigentes de otros gremios, distintos funcionarios, cámaras de comercio y párrocos de la zona. Como vemos, por las características propias del conflicto y de sus consecuencias más inmediatas, el principal soporte social en el que se apoyaron los trabajadores de la carne se ubicó más en el entramado social y comunitario local, que en el colectivo laboral regional. Tengamos en cuenta que del total de las acciones realizadas entre 1969 y 1972 en las que participan los trabajadores de la carne, el 23,3\% se desarrollan en conjunto con otros sectores sociales (en lo fundamental sectores vinculados al comercio, familiares de los trabajadores y a la iglesia), porcentaje ampliamente superior a la media que se puede observar para el conjunto del movimiento obrero en el Gran La Plata (2,1\%). A su vez, son prácticamente marginales las acciones en las que participan sectores del movimiento estudiantil (solo dos hechos), a pesar de ser uno de los sujetos que se encontraba más altamente movilizado en la región durante el periodo. En particular fueron dos las organizaciones que se mostraron más activas a la hora de 
acompañar a los trabajadores a lo largo de todo el conflicto, y las que en última instancia el sindicato terminó privilegiando a la hora de componer su campo de alianzas y apoyos. Estamos hablando de la Cámara de Industria y Comercio de Berisso y de los párrocos de la zona. Si bien el establecimiento de alianzas con grupos y sectores del conjunto de la comunidad local equilibra en algún punto la debilidad en el poder de negociación autónomo de los trabajadores, en nuestra opinión, esta situación termina consolidando la tendencia a que el conflicto no desarrolle mayores grados de radicalidad y combatividad, al tiempo que tampoco parece haber podido conformar un campo de fuerzas lo suficientemente fuerte como para mantener o conservar las fuentes de trabajo. Ambos aspectos se harían particularmente palpables en la finalidad concreta perseguida por esta "comisión de emergencia" y sus resultados. El objetivo consistía meramente en sugerir posibles soluciones a las necesidades más urgentes del personal de las plantas frigoríficas. Finalmente a instancias del informe elaborado por la "comisión de emergencia", el gobierno provincial anuncia un paquete de medidas con el objetivo de crear nuevas fuentes de trabajo, entre las que se encontraban la concesión de un préstamo para la reactivación de la Cooperativa Argentina Textil Ltda de Berisso, la asignación a las comunas de Berisso y de Ensenada de la suma de 2 millones de pesos para la realización de obras públicas que posibilitaran nuevas fuentes de trabajo, y la adopción de medidas financieras para facilitar el pago de los impuestos, especialmente a partir del acortamiento de plazos especiales. Gran parte de las iniciativas anunciadas, finalmente, no tuvieron un impacto concreto e inmediato en la creación de nuevas fuentes de trabajo, ni siquiera apuntaban a resolver el problema central: la crisis de la industria frigorífica.

En verdad, desde el gobierno fundamentalmente se apuntaba a establecer políticas de capacitación y distribución de los trabajadores en otras actividades. Sin embargo, en una región ya golpeada por la desocupación ${ }^{28}$, este tipo de iniciativas generaron algunas tensiones en el interior del propio movimiento obrero de la zona. Cuando se hizo pública y evidente esta finalidad, el sindicato Flota Petrolera del SUPE (Sindicato Unido Petroleros de Estado) emite un comunicado en el que les solicita a los operarios suspendidos del Swift que no cubran vacantes en las dependencias que YPF poseía en Berisso y Ensenada. Esto constituyó una forma de acción solidaria hacia los 2.000 cesantes que se mantenían en conflicto con la empresa estatal desde 1968. De manera similar se pronunciaron los trabajadores de SUPA (Sindicatos Unidos Portuarios Argentinos) Puerto La Plata, quienes en varias oportunidades efectúan críticas a los directivos de los gremios metalúrgicos y de la carne por negarse reiteradamente a alcanzar una solución al problema del ámbito jurisdiccional de trabajo respecto del personal de dichos sindicatos que se desempeñaba en labores netamente portuarias. Quizá sea ésta una de las razones por las cuales el conflicto no logra estructurar un campo de alianza hacia el interior del movimiento obrero de la región, el cual en ningún momento se involucra más allá de algunas declaraciones de solidaridad, y lo hace independientemente de las instancias de articulación entre distintos sectores, que en verdad no exceden muchas veces el marco de la comunidad de Berisso. A dicha circunstancia deberíamos incorporar, además, el hecho de que en el Gran La Plata durante la década del setenta, la inexistencia de una CGT regional organizada y unificada debilitaba aún más las ya escazas tendencias a la coordinación y unificación de las luchas. De todos modos, tampoco la dirección sindical de los trabajadores de la carne orientaba su accionar para estrechar los vínculos con el resto del movimiento obrero. Más aún, como ya señalamos, en ningún momento participó bajo nuestro periodo de estudio de ninguna de las instancias de centralización sindical.

Mientras que desde distintos sectores sociales y listas opositoras dentro del sindicato se proponían planes de lucha más activos que reclamaban la nacionalización de la empresa y en algunos casos la estatización sin pago y bajo administración obrera, la Comisión Directiva del sindicato de Berisso seguía privilegiando las instancias más deliberativas y negociadoras, que en ningún momento escaparon al control de la burocracia sindical. En marzo del año 1971 el gremio convoca a una multitudinaria asamblea, a la que concurren aproximadamente dos mil personas y en la que Guana insiste en que la plena recuperación de las fuentes de trabajo estaba condicionada a la normalización de los arribos de ganado al mercado de Liniers. Puntualiza además que, de no obtenerse la masiva reincorporación de los trabajadores, se estaba gestionaría un régimen 
jubilatorio preferencial para los que no pudiesen reintegrarse a sus tareas. En la ocasión, el secretario general del gremio expresa, como en otras muchas oportunidades, de manera manifiesta y sin reparos de ningún tipo, su vocación conciliadora y participacionista. Luego de reseñar todas las gestiones realizadas señalaba que: “todos los trámites fatigosos que demande la solución del problema serán realizados, aunque la crítica fácil de quienes reclaman movilizaciones sin saber para qué, nos acusen de negociadores" ( El Día, 17/03/1971 ). No tendríamos demasiados elementos para suponer que desde las bases surgiera un cuestionamiento generalizado al discurso que el secretario general hacía público en reiteradas ocasiones. En esta misma asamblea multitudinaria que estamos reseñando, una vez concluida la exposición, Guana declaró abierto el debate y dos oradores aprovecharon la oportunidad para expresar una crítica severa y directa a la actuación gremial. El primero la caracterizó de "negociadora y quedantista", mientras que el segundo además exhortó a los trabajadores del Swift a que siguieran la actitud de los trabajadores de Córdoba. No obstante, según la crónica periodística, "pudo observarse como en ambas oportunidades quienes tomaron la palabra debieron soportar el abucheo de la concurrencia, haciendo abandono del estrado en medio de demostraciones de adhesión a los dirigentes sindicales" ( El Dia, 17/03/1971). El apoyo de las bases a la estrategia negociadora y dialoguista de la cúpula gremial se podría corroborar asimismo analizando las elecciones que tuvieron lugar al mes siguiente, desarrolladas bajo el contexto de un incipiente pero lento incremento de la actividad de en la planta del Swift ${ }^{29}$. En los comicios realizados en 1971, la lista Rosa oficialista no solo logra nuevamente mantener la conducción del gremio, sino que gana los mismos con bastante holgura. Guana se impuso en las elecciones con 5.160 sufragios contra 475 de la lista Blanca y Celeste, mientras que se registraron 70 votos en blanco y 15 anulados. En la ocasión, el secretario general refrenda, y hasta profundiza -podríamos sostenerlos conceptos que había sostenido en oportunidades anteriores: "no me importan críticas que algunos sectores me formulan (...) no se logra nada con propiciar una estatización inmediata, un plan de lucha y la movilización de los obreros. Es un problema nacional y debemos estar contentos que no se hayan producido despidos. El pago de la garantía horaria es un paliativo" ( ElDía, 27/04/71).

Independientemente de las vicisitudes de este momento en particular, el escaso cuestionamiento de las bases a la dirección sindical es señalado también en varias ocasiones por la inteligencia policial. Según los informes de la policía, hacia 1973 la Comisión Directiva del sindicato gozaba "de un gran apoyo de los afiliados, debido a su buena administración demostrada a través del tiempo” 30 (DIPBA, Mesa B, Factor Gremial, Legajo 11. Tomo 4. Localidad Berisso, 09/04/1973, p. 8).

\section{La junta de aCreedores. Finales de una etapa}

El conflicto se introduce en una nueva y final etapa en los momentos preliminares a la fecha fijada para la convocatoria de acreedores que se llevó a cabo finalmente el 4 de octubre de 1971. El juez a cargo de la misma era el Dr. Salvador María Lozada. Uno de los aspectos más interesantes de este proceso es que derivó en una serie de estudios necesarios para evaluar la condición económica de la empresa y la acción de los distintos actores, que terminó dando a luz la verdadera situación respecto al confuso estado de la contabilidad de la empresa, los perjuicios que habían ocasionado las compras del Armour y La Blanca, y la operatoria que permitía la transferencia de ganancias a Deltec, la cual mermó las posibilidades del propio frigorífico (Gresores, 2002).

Las vicisitudes que signaron el desarrollo de la convocatoria de acreedores determinaron en parte que el SOEICB volviera a alinearse con la empresa, en contra del juez, ganaderos y consignatarios que actuaban como acreedores. Días antes de que tuviera lugar la asamblea se produce un diferendo respecto a las cartas poderes en manos de trabajadores del Swift. Un grupo de abogados que patrocinaban a obreros del Swift denunció que la compañía había intimado al personal a que votaran a favor de la empresa -a fines de conservar la fuente de trabajo - en la junta de acreedores, para lo cual en teoría los habían obligado a firmar una carta poder en blanco. Ante la denuncia, el juez interviniente separó a los directores de la compañía Swift, nombró 
interventores e intimó asimismo al SOEICB a que presentaran en el juicio de la convocatoria de acreedores la totalidad de las cartas poderes para votar en el mismo. Como respuesta el gremio convoca a una asamblea de la que participaron 2.000 personas en la que se criticó fuertemente la actitud del juez y de los ganaderos y consignatarios. Nuevamente se manifestó la concordancia con los planeos de la empresa. Se pronunciaron en contra de la quiebra de la compañía y por el mantenimiento de las fuentes de trabajo: "si para defender los intereses de los trabajadores del Swift hemos tenido que defender directamente al frigorífico, no tenemos ningún empacho en reconocerlo (...) ¿es que acaso los ganaderos nos garantizan otro trabajo en reemplazo del que tenemos?” (ElDía, 24/09/1971). Aclararon además que si el Estado no ofrecía garantías que aseguraran la conservación de la fuente de trabajo, iban a votar aceptando el concordato.

Finalmente el 4 de octubre en la asamblea de acreedores, realizada en el teatro San Martín de Capital Federal, ${ }^{31}$ se aprobó el concordato con el 85,6\% de los créditos verificados por la sindicatura. Según El Día, en el resultado gravitó decididamente la posición asumida por los bancos oficiales y privados, las instituciones financieras del exterior y los obreros de las plantas de Berisso y Rosario. Los que se manifestaron en contra fueron los representantes de la Cámara Argentina de Martilleros y Consignatarios de Hacienda, y los centros de consignatarios de Córdoba y Santa Fe.

Una vez votado el concordato la presión de distintos sectores estuvo dirigida a que el juez homologara rápidamente el mismo. Entre estos sectores se encontraba el propio Gobierno Nacional que, desde la asunción a la presidencia del general Lanusse, había virado en su posición inicial respecto al diferendo ${ }^{32}$. Sin embargo, y a pesar de las presiones, un mes después el juez Lozada finalmente rechazó el concordato, declaró la quiebra del Swift y designó como liquidador al Estado Nacional en la persona del PEN. El PEN, a su vez, dispuso por decreto la continuación de la actividad industrial y comercial, y nombró como administrador a Miguel Busquet Serra, un hombre estrechamente vinculado con el mundo rural. Conocida la decisión del juez, el sindicato de Berisso convocó a una multitudinaria asamblea que resolvió declarar en estado de alerta al gremio. Si bien tanto Guana como Zorila consideraron de manera positiva el fallo, manifestaron la necesidad de que el gobierno brindara el apoyo financiero necesario para asegurar la continuidad operativa de las plantas de Berisso y Rosario. Como en oportunidades anteriores resurgieron puntos de vista opuestos respecto al futuro del frigorífico. Mientras que el dirigente de la Federación Nacional se manifestó a favor de que el Estado, el personal obrero, directivos y técnicos argentinos de la compañía en su conjunto se hicieran cargo del frigorífico, nuevamente Guana se pronunció públicamente en contra de la intervención estatal, por entender que ello colocaría a la empresa en la "misma situación que padecen los ferrocarriles" (El Día, 09/11/1971), y especificó que la dirección de la compañía debería ser asumida en parte por su personal, pero también por sus acreedores.

Si bien en los primeros meses la administración del nuevo interventor fue evaluada de manera auspiciosa, un año después de la convocatoria de acreedores, el sindicato volvió a calificar nuevamente la situación como desalentadora, debido a "la falta de perspectiva de una solución definitiva al caso Swift" (El Día, 03/10/1972). La "solución definitiva al caso Swift" que finalmente tuvo lugar, no fue sin embargo la que pretendía el sindicato. Luego de una larga agonía, durante la cual el frigorífico continuó con "su actividad bajo control del Estado con una gestión dispar que produjo grandes pérdidas económicas que se tradujeron en progresivas erogaciones del fisco" (Gresores, 2002, p. 374) -y que incluyó una reprivatización en 1977-, el mismo terminaría cerrando sus puertas de manera definitiva en 1983.

\section{Conclusiones}

Una de las particularidades del caso que acabamos de analizar estriba, en nuestra opinión, en que independientemente de la gravedad e intensidad de la crisis evidenciada, el conflicto analizado no se ajusta a las experiencias más espectaculares o a los casos más paradigmáticos del ciclo de protesta social y radicalización política que tuvo lugar en la Argentina durante la década del sesenta y setenta. De manera que focalizarnos 
en este caso nos permitió acceder y problematizar algunas de las modalidades de acción y estrategias del movimiento obrero, que muchas veces aparecen solapadas en algunos de los análisis sobre el periodo.

Desde nuestro punto de vista, la dinámica específica que adquirió la conflictividad laboral de este colectivo de trabajadores industriales no se puede escindir, en primer lugar, de la particular situación por la que atravesaba la actividad en la que estaban insertos. En el caso analizado hemos podido observar cómo un sindicato que representaba una organización de mayor antigüedad ya consolidada, pero que se encontraba debilitada desde el punto de vista estructural (como consecuencia del estancamiento o crisis que exhibían las consideradas ramas vegetativas de las que formaban parte) sufrió sensiblemente la disminución de su poder de negociación, lo cual en parte explica la dinámica y el resultado del conflicto suscitado. En este punto quizá deberíamos introducir un matiz, en tanto que, si bien los trabajadores de la carne de Berisso no lograron en el largo plazo detener la tendencia a la disminución del salario (sobre todo en comparación con trabajadores de otras industrias) ni tampoco conservar la fuente de trabajo, de todos modos en la coyuntura que analizamos consiguieron concretar el objetivo de mínima: evitar el cierre del establecimiento y el pago de las garantías horarias para los trabajadores suspendidos, lo que les permitió conservar cierto nivel de empleo y de ingreso, por lo menos en lo inmediato.

En el caso que analizamos, el poder de negociación no solo se debilita, sino que además la capacidad de enfrentamiento también se resiente, ya que como vimos, el conflicto no desembocó nunca en grandes procesos de lucha o movilizaciones desde las bases, sino que se circunscribió a los canales de negociación institucional entre dirigentes gremiales y las patronales o autoridades nacionales y provinciales. De manera que podríamos sostener que en las ramas en crisis no solo el poder de negociación de los trabajadores disminuye sensiblemente, sino que además sucede lo mismo con su capacidad de enfrentamiento, es decir su nivel de militancia.

Igualmente deberíamos aclarar otro aspecto. Esta debilidad en el poder de negociación que estamos mencionando se vincula más con el aspecto estructural del concepto que a lo referido a lo que hemos conceptualizado como el "poder asociativo", ya que los trabajadores de la carne de Berisso contaban, durante nuestro periodo de análisis, con una sólida organización gremial, reconocida tanto por el Estado como por la propia burguesía, hecho que daba cuenta de un grado de institucionalización considerable. En este caso la escasa correlación entre lo que Wright denomina poder asociativo y militancia obrera se podría explicar, a término de hipótesis, a partir de la idea de que dicho sindicato, como expresión de un sindicalismo de mayor antigüedad -es decir más consolidado y más centralizado en términos institucionales- fue más proclive a establecer una conducción "responsable" de la masa trabajadora. La dirigencia sindical se mantuvo siempre en posiciones colaboracionistas, fuera tanto con la patronal como con el Estado. Aunque es cierto también que las posibilidades de concretar o impulsar cualquier tipo de paro o huelga no eran las más propicias, en tanto que el cierre o paralización de los establecimientos tornaba a las mismas un tanto abstractas.

Esta debilidad en el poder de negociación no fue contrarrestada o compensada por una consolidada alianza con el movimiento obrero de la región, ya que independientemente de algunas expresiones de solidaridad y participación en instancias deliberativas, los conflictos no obtuvieron demasiado apoyo del campo gremial regional. Pensamos que no son ajenas a esta situación las tensiones que pudimos observar entre los distintos sectores, en un contexto regional en el que el mercado de trabajo evidenciaba ciertos desequilibrios, aunque el índice de la tasa de desocupación no fuera particularmente alto. Por el contrario, el conflicto se caracterizó por haber gestado fuertes solidaridades con otras fracciones sociales, que comprometieron al entramado social y comunitario local. En este punto, podemos observar como la debilidad en el poder estructural autónomo de los trabajadores es equilibrado a partir de alianzas con grupos y sectores del conjunto de la comunidad local. Aunque, de hecho, esta situación terminó consolidando la tendencia a que los conflictos no desarrollaran mayores grados de radicalidad y combatividad, y se circunscribieran a las pautas establecidas dentro de los marcos institucionales legales. A esta última circunstancia también contribuyó, como vimos, la actitud y 
accionar que evidenciaron tanto las patronales como el propio Estado, más propensas a establecer canales de negociación con la representación gremial que a desplegar una intransigencia antisindical.

A título de hipótesis se podría sostener que la dinámica y resultado final que presentó el caso de los trabajadores de la carne estuvo determinada entonces por el debilitamiento desde el punto de vista estructural que afectaba a dicho sector, como consecuencia en parte de dos factores. Uno de más largo plazo y que está referido a la precariedad que signaba a la experiencia obrera de los frigoríficos en sí misma (Lobato, 2004), ya sea tanto por la inestabilidad laboral propia de la actividad como por el alto nivel de rotación en los equipos de trabajo $^{33}$. A dicha circunstancia se le suma, por añadidura, la crisis particular de la que adolecían los grandes frigoríficos al estilo del Swift hacia los años 70. Todos estos elementos fueron comprometiendo el poder de negociación de los trabajadores de la carne, a punto tal que, en el largo plazo e independientemente de las diversas tácticas desplegadas, no lograron conservar sus fuentes de trabajo.

\section{BiBliografia}

Banco de la Provincia de Buenos Aires (1981). Reseña histórico-económica de los partidos de la provincia de Buenos Aires. Buenos Aires: Editorial Sabalain.

Bretal, E (2016a). La Edad de Oro en las representaciones de ex\#obreros del frigorífico Swift de Berisso. Trabajo y sociedad, (27), 291-304. Recuperado en 01 de noviembre de 2017, de http://www.scielo.org.ar/scielo.php?scrip $\mathrm{t}=$ sci_arttext\&pid=S1514-68712016000200018\&lng=es\&tlng=es.

Bretal, E (2016b). El ocaso de Swift en Berisso: representaciones de ex-obreros sobre las tensiones entre el capital y el trabajo. Revista THEOMAI / THEOMAI Journal Estudios criticos sobre Sociedad y Desarrollo / Critical Studies about Society and Development. (33) (segundo semestre de 2016) Recuperado el 02 de noviembre de 2017 http: //www.revista-theomai.unq.edu.ar/NUMERO_33/7.\%20Art_Eleonora_Bretal.pdf.

Bretal, E (2011). Memorias y experiencias de obreros/as de la carne sobre una época "brava": "los compañeros que se iban yendo" y la "degradación" del Swift en Berisso". Revista THEOMAI / THEOMAI Journal Estudios críticos sobre Sociedad y Desarrollo / Critical Studies about Society and Development. (24). Recuperado 02 de noviembre de 2017 http://revista-theomai.unq.edu.ar/NUMERO\%2024\%20(traba-antropo)/3.\%20Eleonora\%20Bretal. pdf

Castillo, C. (2011). El PRT-La Verdad entre los trabajadores de la carne de Berisso: La agrupación El Activista de la Carne y la Lista Gris [1967-1972]. Cuestiones De Sociologia, (7). Recuperado de http://www.cuestionessociolo gia.fahce.unlp.edu.ar/article/view/CSn07a12

Dawyd, D. (2011). Sindicatos y política en la Argentina del Cordobazo. El peronismo entre la CGT de los Argentinos y la reorganización sindical (1968-1970). Buenos Aires: Editorial Pueblo Heredero.

Dawyd, D y Nassif, S (2013). Fuentes para el estudio del movimiento obrero: El Servicio de Documentación e información Laboral (DIL), dirigido por Leonardo Dimase (1960-1976, 1982-1989). Corpus. Archivos virtuales de la alteridad americana 3 (2). Recuperado de https://corpusarchivos.revues.org/604.

Flier, P. (2015). Historia Reciente y desafíos de las fuentes: el Archivo de la Dirección de Inteligencia de la Policía de la Provincia de Buenos Aires (DIPBA). Travesía (San Miguel de Tucumán), 17 (2), 81-88. Recuperado en 24 de enero de 2018, de http://www.scielo.org.ar/scielo.php?script=sci_arttext\&pid=S23147072015000200004 \&lng=es\&tlng=es.

Ghigliani, P (2012). Archivos policiales e historia social del trabajo: los archivos de la Dirección de Inteligencia de la Policía de la Provincia de Buenos Aires (Argentina). Una aproximación al problema. II Seminário Internacional Mundos do Trabalho, Rio de Janeiro.

Gresores, G (2002). El vaciamiento de las empresas de capital extranjero en la Argentina ¿Una historia reiterada?. Portal de promoción y difusión pública del conocimiento académico y cientifico. Recuperado de http://nulan.mdp .edu.ar/2331/1/gresores.2002.pdf. 
Gresores, G (2001). Conflictos obreros en la industria frigorífica bajo la dictadura militar: la huelga larga del Swift en Berisso. Ciclos, 11(22). Recuperado de http://bibliotecadigital.econ.uba.ar/download/ciclos/ciclos_v11_n22_ 03.pdf.

Izaguirre, I y Aristizabal, Z. (2002). Las luchas obreras 1973 - 1976. Documento de trabajo No17, Buenos Aires, Instituto de Investigación Gino Germani. Facultad de Ciencias Sociales. UBA.

Izaguirre, I (2009). Las luchas obreras y el genocidio en la Argentina. En I. Izaguirre et al, Lucha de clases, Guerra civil $y$ genocidio en la Argentina. Buenos Aires: Eudeba.

James, D (2004). Doña María. Historia de vida, memoria e identidad politica. Buenos Aires: Manantial.

Kosacoff, B (2009). Marchas y contramarchas de la industria argentina (1958-2008). Boletín Informativo Techint 330.

Lobato, M (2004). La vida en las fábricas. Trabajo, protesta y política en una comunidad obrera, Berisso (1904-1970). Buenos Aires: Prometeo Libros.

Nava, A y Romá P. (2011). Apuntes para el estudio de conflicto obrero-estudiantil en La Plata, Berisso y Ensenada durante las décadas del sesenta y setenta. Conflicto Social, 4 (5). Recuperado de http://webiigg.sociales.uba.ar/c onflictosocial/revista/05/13_nava-roma.pdf.

Nieto, A (2016). Narrativas sobre la historia obrera en Argentina. Notas críticas y apostillas conceptuales. Herramienta web 18. Recuperado de http://www.herramienta.com.ar/autores/nieto-agustin.

O’Donnell, G (2009). El Estado Burocrático Autoritario, 1966-1973. Buenos Aires: Prometeo Libros.

Raimundo, M (2015). Radicalización obrera a fines de los años ` 60 en Argentina: aproximaciones desde una historia comparada. Revista Esboços, 22 (33), p. 52-74. Recuperado de https://periodicos.ufsc.br/index.php/esbocos/ar ticle/view/2175-7976.2014v22n33p52

Robles, H (2009). La Plata en las vísperas montoneras: una reconstrucción de las condiciones sociales y políticas de la masificación y radicalización política de la JP platense y su articulación con montoneros (1970-72). Cuestiones de Sociologia, Nros. 5/6, La Plata, Prometeo.

Schvarzer, J (1996). La industria que supimos conseguir. Una historia politica-social de la industria argentina. Buenos Aires: Planeta.

Silver, B J. (2005) Fuerzas del trabajo. Los movimientos obreros y la globalización desde 1870. Madrid: Akal.

Tortti, MC (2003). Protesta social y “nueva izquierda” en la Argentina del “Gran Acuerdo Nacional”, en Camarero, $\mathrm{H}$; Pozzi, P y Schneider, A, De la revolución libertadora al menemismo. Historia social y politica argentina. Buenos Aires: Ediciones Imago Mundi.

Treviño, P (1972). La Carne Podrida. Buenos Aires: Del Salto.

Vázquez, H (1983). Conflictos laborales en La Plata, Berisso y Ensenada. Manuscrito no publicado.

Vogelman, V (2013). Los trabajadores de la carne del Gran Rosario. Organización gremial y conflictividad laboral 1969-1976. Historia regional (31). Recuperado de: http://historiaregional.org/ojs/index.php/historiaregional/ article/view/34/166.

Wright, E. O. (1983). Clases, crisis y estado. Madrid: Siglo XXI.

Wright, E. O. (2000). Working-Class Power, Capitalist-Class Interests, and Class Compromise. American Journal Of Sociology 105, 4K. The University of Chicago.

Zorilla, R (1974). Estructura y dinámica del sindicalismo argentino. Buenos Aires, La Pléyade.

- Diario El Día, La Plata, 1968-1972

- Dirección de Inteligencia de la Policía de la Provincia de Buenos Aires (DIPBA): "Sindicato de la carne". Mesa B, Factor Gremial, Legajo 11. Tomo 3. Localidad Berisso.

- Informes Laborales del Servicio de Documentación e Información Laboral (DIL), dirigido por L. Dimase. No 92 (octubre de 1967); No 95 (Enero de 1968); 114 (Agosto de 1969); 128 (Octubre de 1970)

- INDEC “Encuesta Permanente de Hogares”, onda 1974. 


\section{Notas}

1 Cuando nos referimos a la región del Gran La Plata, hacemos alusión al espacio que conforman los municipios de La Plata, Berisso y Ensenada, ubicado en el extremo sureste de lo que se conoce como la Región Metropolitana de Buenos Aires. Hacia la década del setenta el desarrollo institucional y económico determinaron que el triángulo urbanístico, industrial y comercial constituido por las ciudades de La Plata, Berisso y Ensenada adquiriera una envergadura tal que le confería al área la categoría de centro nacional (Banco de la Provincia de Buenos Aires, 1981), para conformar un polo provincial con identidad y dinámica propias (Robles, 2009), aunque presentaba, asimismo, características similares a la de los grandes centros urbanos e industriales del país.

2 Tengamos en cuenta que la primer dificultad que afrontamos quienes intentamos elaborar series cuantitativas sobre conflictividad laboral en la historia reciente argentina es la ausencia de registros oficiales sobre la misma a nivel nacional y a largo plazo, tal como cuentan algunos pocos países del centro de la economía capitalista. En este sentido, las fuentes hemerográficas presentan la ventaja, tal como sostienen Izaguirre y Aristizabal (2002), de que a pesar de ser una fuente secundaria (por ende la menos apta para realizar un ejercicio de seriación), de todas formas es un soporte empírico de fácil acceso y un medio lo bastante estandarizado que ofrece una variedad de información de lo social muy amplia, lo que facilita el establecimiento de distintos tipos de "control" metodológico para disminuir el carácter "intencional" o "ideológico" que inherentemente posee. En un trabajo anterior (Nava y Romá, 2011) hemos especificado el procedimiento, las decisiones y problemas teóricos-metodológicos que se derivan del análisis cuantitativo de la lucha de clases y que lo fundamentan.

3 Con respecto a esta fuente véase Dawyd y Nassif (2013).

4 Con respecto a los desafíos, perspectivas y limitaciones que presenta este tipo de archivo véase Ghigliani (2012) y Flier (2015). En particular, los expedientes de la DIPBA nos han permitido acceder a dos tipos de documentación. En primer lugar, a material de origen obrero como volantes, declaraciones, comunicados, informes, prensa, boletines, boletas electorales, etc., que fueron recogidos por la propia policía. Por otro lado, también nos brinda documentación de origen policial, es decir, informes de asambleas, comisiones directivas, reuniones, conflictos, manifestaciones, análisis de situación, resultados electorales y otros informes de espionaje en general. Si bien este archivo nos permite contar con cierto tipo de información a la que no es muy simple acceder, debemos tener presente que, como señala Ghigliani, las dificultades a la hora de establecer con precisión cuáles son las condiciones de producción de este tipo de documentación nos obligan a extremar los recaudos críticos en su uso como fuente historiográfica.

5 Cabe señalar que no estamos sugiriendo una relación unicausal y lineal entre poder de negociación y nivel de militancia o radicalidad de la conflictividad laboral (véase en el mismo sentido Silver, 2005). Como aclara el mismo Wright, existen "obviamente muchos otros factores que determinan la actividad real dentro de la lucha de clases dejando aparte la capacidad de lucha” (Wright, 1983, p. 94).

6 Número que en algunos momentos alcanzó hasta los 10.000 o 15.000 operarios (Lobato, 2004).

7 Según Guillermo O 'Donnell, la creciente hostilidad entre el gobierno de la Revolución Argentina (1966-1973) y la burguesía ganadera se convirtió en un "magno problema agravado por el escándalo Swift-Deltec” (O'Donnell, 2009 , p. 261).

8 Sobre la huelga véase Lobato (2004, pp. 297-300).

9 Con posterioridad, casi todas las listas opositoras a la conducción del sindicato van a presentar como un reclamo central la vigencia de las conquistas obtenidas por "el convenio del 46", entre las que mencionan: "delegados, comisiones internas, garantía horaria, ley de maternidad, jornada legal de ocho horas, trato humano en las secciones” (DIPBA, Mesa B, Factor Gremial, Legajo 11. Tomo III. Localidad Berisso, mayo de 1965, p. 51).

10 De todos modos, en la siguiente elección llevada a cabo en el año 1967, nuevamente estas tendencias participaron con listas propias.

11 Si bien el secretario general de la Federación suele expresar hacia 1970 un discurso político más combativo que el del sindicato de Berisso, dicho dirigente se alinea en un principio en el sector más dialoguista con el gobierno de la "Revolución Argentina", lo cual nos habla de lo volátiles que resultaban ser los distintos alineamientos sindicales. Deberíamos tener en cuenta que, como sostiene Lobato, históricamente las relaciones entre el sindicato de Berisso y la Federación de la Carne estuvieron signadas por distintos grados de tensión y distanciamiento, en parte por motivo de que la Federación se encontraba hegemonizada por los gremios de las pequeñas empresas.

12 Algunos sectores de la prensa escrita señalaban que el propio Balbín intervino activamente en las elecciones del sindicato en 1965, en apoyo a la lista de Héctor Guana, en consonancia con una supuesta estrategia del gobierno nacional de Illia de tener sindicatos alineados con la UCRP, con el objetivo de lograr una CGT no peronista. (véase Crónica, 11/05/1965).

13 Cabe aclarar que no negamos el papel insoslayable que todos los sindicatos tienen en el plano político, simplemente estamos aludiendo al modo discursivo en el que el gremio se presentaba frente a sus afiliados. 
14 Las otras dos tendencias estaban representadas por la "negociación" y la "oposición frontal". Con respecto a esta caracterización véase Dawyd (2011, p. 17) y Nava (2017).

15 Es necesario aclarar que si bien su identificación con el PRT- La Verdad, es indubitable, en algunas ocasiones de campaña electoral solía desmentir públicamente que la Lista Gris fuera de tendencia "trotzkystas"(sic), señalando que a la hora de ser conformada "dejó de lado todo partidismo política" (DIPBA, Mesa B, Factor Gremial, Legajo 11. Tomo III. Localidad Berisso, 06 /09/1967, p. 271).

16 Para un análisis en mayor profundidad sobre esta tendencia véase Castillo (2011) y Raimundo (2015)

17 Por otro lado, los comicios en el sindicato de la carne de Berisso se caracterizaban en general por presentar un alto nivel de participación, cercano al $80 \%$ y $90 \%$ de los empadronados.

18 Esta misma curva en forma de U invertida también puede divisarse en el plano nacional, si tenemos en cuenta los datos brindados por O’Donnell (2009, p. 394) o por Korzeniwicz (1995)

19 Excluyendo las ocasiones en las que adhieren a las huelgas generales decretadas por la CGT (como por ejemplo la que se efectúa el $1^{\circ}$ de julio 1969), solo en marzo de 1970 los empleados de la sección rectores del Swift mantienen un conflicto con la empresa, generado por la insalubridad de las tareas debido a las altas temperaturas y humedad en la sección, que deriva en un paro de dos días en esa sección. La dirección del sindicato se manifiesta en contra de la medida de fuerza. En una asamblea de 120 personas en la que se reclama la reducción del horario de trabajo a 8 horas hasta tanto se solucione el problema, se acusa a los directivos del sindicato, ya que "se limitaron a repetir el planteo de la patronal, que consiste apunta - en que sigamos trabajando igual que ahora, con el pago de algunas horas extras para descanso con la promesa de que dentro de cuatro meses exista una solución" (El Día, 06/03/1970).

20 De las acciones restantes el $46 \%$ corresponden a declaraciones, solicitadas, etc.

21 Hay un foco de conflictividad que, independiente de que en parte se escapa al registro cuantitativo que hemos elaborado, no por ello carece de importancia, tal como se desprende de la lectura de los informes de inteligencia policial. De estos archivos se infiere que el accionar de los médicos de la empresa (que debían certificar las licencias por enfermedad) era un blanco frecuente de las quejas de los trabajadores en las mismas plantas. En general, en la industria frigorífica la cuestión referida a la insalubridad de las tareas es un motivo frecuente de conflictividad. El propio gremio de Berisso denunciaba que el $60 \%$ o $70 \%$ de las tareas en los frigoríficos Swift y Armour podían ser consideradas tareas insalubres (DIPBA, Mesa B, Factor Gremial, Carpeta 16. Legajo 11. Tomo 3, Localidad Berisso, p. 256). De todos modos, la posibilidad concreta del cierre de los establecimientos hacia 1970 deriva en que el problema de las fuentes de trabajo opaque las demás demandas.

22 Si bien en momentos previos a nuestro periodo tanto la Lista Blanca y Celeste como la Lista Gris acusan a la conducción de utilizar "matones" para agredir físicamente a los opositores en las asambleas (DIPBA, Mesa B, Factor Gremial, Carpeta 16. Legajo 11. Tomo 3, Localidad Berisso, agosto de 1966 y marzo de 1967, pp. 117 y 184), por lo menos entre 1969 y 1972 las reuniones del gremio transcurren en un clima de cierta normalidad.

23 A fines de octubre, la Federación Gremial denunciaba que los trabajadores afectados (entre cesanteados y suspendidos) eran alrededor de 30.000 .

24 Uno de los casos más representativos que podríamos citar es el despido en 1968 de los hermanos Kowalczuc, quienes se encontraban entre los dirigentes más activos de la agrupación El Activista de la Carne.

25 Habría que señalar de todos modos que el ejecutivo provincial se mostró, por el contrario, mucho más predispuesto y activo para intervenir en el diferendo.

26 Lobato, por su parte, sostiene que si bien las plantas frigoríficas de Berisso fueron grandes empresas con modernos procesos de producción en sus comienzos, a partir de la década del sesenta las compañías "demostraron escaza flexibilidad para adaptarse a los cambios, realizar nuevas inversiones de capital e incorporar las nuevas tecnologías” (Lobato, 2004, p. 294). Sin embargo, es interesante señalar que de los testimonios orales analizados por Bretal se desprende la alta estima con que los exobreros de los frigoríficos de Berisso se referían al buen funcionamiento y administración de la fábrica "cuando estaba en manos de los ingleses" (Bretal, 2016a).

27 Uno de los modos en el que agrupamos los fines que se expresan en las luchas intentó captar las tendencias en los "alineamientos" expresados por las distintas fracciones obreras en relación a las alternativas presentes en el ciclo de protesta más general que se desarrollaba en el plano nacional y su posicionamiento más concreto con respecto al régimen militar. Siguiendo en parte el análisis que realizan Izaguirre y Aristizabal (2002), hemos decidido agrupar los fines en tres categorías: rechazo formal/en disputa; a favor del régimen militar y contra el régimen militar. En esta última categoría se incluyeron todos los enfrentamientos en los cuales se expresaba un rechazo sustancial y directo al programa económico, político y social que llevaba adelante la dictadura militar durante aquellos años, propugnando además la modificación esencial del mismo independientemente de que se cuestionara (o no) explícitamente la existencia misma del sistema capitalista. Un criterio inverso se utilizó para delimitar la segunda categoría. Por su parte, en la primera categoría ubicamos los enfrentamientos en donde los objetivos explícitos cuestionaran aspectos parciales sin llegar a proponer una alternativa política y económica diferente a la puesta en práctica por el gobierno. 
28 Deberíamos tener en cuenta que en el general el índice de desocupación no era particularmente alto en la zona. En promedio, entre los años cincuenta y los ochenta, la tasa de desocupación para el Gran Buenos Aires y el total de los de aglomerados urbanos fue del $5 \%$ (Kosacoff, 2009, p. 104). Según los datos brindados por el diario El Día, la tasa de desocupación del Gran Buenos Aires para 1968 era del 4,8 \% (El Día 12/01/1969). En lo que respecta específicamente a la región del Gran La Plata, el primer dato disponible de desocupación es para el año 1974. Para dicho año la tasa de desocupación se ubica en un valor bastante bajo, 3,4\% (Encuesta Permanente de Hogares, abril 1974). De todos modos, el problema del desempleo no se encontraba ausente en el panorama regional ni en el nacional, dados ciertos procesos que afectaban el nivel de empleo, vinculados tanto a la crisis que sufrían algunas industrias de las consideradas ramas vegetativas, como al proceso de racionalización del Estado que se proponía llevar adelante el gobierno de la "Revolución Argentina”.

29 En el mes de abril de 1971, sobre un total de 5.629 operarios que se desempeñaban antes del conflicto, se encontraban trabajando aproximadamente 1.650 .

$30 \mathrm{El}$ positivo impacto que tenía en la masa de afiliados una buena administración del carácter mutualista del sindicato es corroborado por los testimonios orales de trabajadores analizados por Verónica Volgelmann, para un caso similar al nuestro: el de los trabajadores de la carne del Gran Rosario durante 1969-1976 (Vogelmann, 2013).

31 El lugar elegido para efectuar la asamblea da cuenta de la trascendencia que había adquirido el conflicto.

32 Resulta sugestivo el hecho de que el Swift era presidido en este momento por un primo del nuevo presidente de la Nación.

33 En este punto deberíamos agregar la mención que hace Lobato respecto a "las divisiones que se establecían entre el pequeño grupo de los trabajadores calificados y la masa de peones” (Lobato, 2004, p. 205) 